\title{
Alcohol use and psychological wellbeing of health workers in a Nigerian Hospital: An exploratory study
}

\section{Adetunji Obadeji, Lateef O. Oluwole, Mobolaji U. Dada, Michael A. \\ Oshatimi}

Department of Psychiatry, Ekiti State University Teaching Hospital, Ado-Ekiti, Ekiti State, Nigeria.

Correspondence: Dr. A. Obadeji; doctunjioba@yahoo.com

\section{Abstract}

\section{Background}

The degree of alcohol use influences one's mental health and psychological wellbeing. Psychological well-being of health workers, however, is crucial to the quality of care their patients receive.

Aims

The aim of this study was to determine the pattern of alcohol use and factors associated with psychological well-being of health care workers at a University Teaching Hospital.

Methods

This was a cross sectional survey of health workers in the medical and surgical specialties at the State University Teaching Hospital in Nigeria. Socio-demographic questionnaire, the 10-items Alcohol Use Identification Test (AUDIT) and the 12-items General Health Questionnaire (GHQ-12) were used to assess socio-demographic, alcohol use and psychological well-being of the participants. Statistical analyses were done using the Statistical Package for Social Sciences (SPSS) version 16. Appropriate statistical tools were used to determine relationships between various variables.

Results

A total of 256 participants were interviewed. Fifteen (5.9\%) of the respondents were either hazardous or harmful drinkers. Psychological distress was reported among $17.2 \%$ of the respondents and this was significantly associated with marital status, years of practice, specialty of practice, presence of ongoing chronic illness, current stressors and level of alcohol use.

Conclusion

A high proportion of the participants in the study were abstainers and a significant number were experiencing psychological distress. Psychological distress was however found to be significantly associated with harmful alcohol use, some socio-demographic variables, and work related factors. Efforts should be geared towards identifying these factors so as to ensure effectiveness and well-being of health workers.

\section{Introduction}

Alcohol mis-use is a major public health problem globally with attendant physical, social and psychological consequences $^{1}$. In Nigeria, several studies have looked at alcohol use in various populations, notably urban and rural dwellers, ${ }^{2,3}$ students in higher institutions $s^{4,5,6}$ and artisans ${ }^{7}$. However, only few studies have looked at alcohol use among health workers. In other populations, factors such younger age, male gender, employment, socio-economic status and psychological distress have been reported to be associated with harmful alcohol use.

Among health workers on the other hand, there were limited studies, the few majorly among doctors ${ }^{8,9}$. In a study by Issa et al among doctors, ${ }^{8}$ about $4 \%$ of the doctors were hazardous users, while heavy workload was significantly related to hazardous drinking; moreover, no association was found between alcohol mis-use and socio-demographic factors. However, this study was limited to hospital doctors.

Studies have shown association between hazardous alcohol use and psychological distress among various populations ${ }^{6,10,11}$. People who abuse alcohol often suffer psychological distress and people who suffer psychological distress may also abuse alcohol. The work of health care professionals places them at risk of both physical and mental health problems from excessive workload and intense stresses experienced daily in their practice among others ${ }^{12}$.
The negative social consequences of alcohol consumption and stressful life events, may trigger psychological, biological or behavioral responses that may interfere with the individual's ability to adapt thus leading to emotional distress reactions and occupational impairment ${ }^{13,14}$.

Psychological distress or psychiatric morbidity, may result from either social or work-related factors ${ }^{8,15}$. Similarly, a health worker who experiences alcohol and other drug problems may pose a risk to patients as a result of intoxication, impaired judgment, prescription errors or unsafe practice ${ }^{16,17}$. Gender, personality traits and psychological distress were important factors influencing hazardous alcohol use $\mathrm{e}^{8,18,19}$.

There are limited studies looking at the pattern of alcohol use and its relationship with the psychological well-being of health workers in sub-Saharan Africa. This study aimed at looking at the pattern of alcohol use, its relationship with psychological distress and factors influencing psychological well-being of health workers in a teaching Hospital in Nigeria.

\section{Methods}

\section{Study design and setting}

This was a cross-sectional survey involving all doctors, nurses in the medical specialties (Medicine, Paediatrics and Psychiatry) and those in the surgical specialties (surgery, Obstetrics and Gynaecology, accident and emergency), 
pharmacists and laboratory scientists, all aged 65 years and below in the service of State University Teaching Hospital in Ado-Ekiti, Nigeria. The Teaching hospital was established in 2008 by upgrading an existing general Hospital. It was to serve as the clinical teaching arm of the College of Medicine of Ekiti State University.

The participants were essentially selected based on similarity in their duties i.e. on call or shift duty. Nurses in the in the outpatient-clinics where shift duty was not done were excluded. The potential for psychological distress or morbidity was measured by the General Health Questionnaire version 12 (GHQ-12) and for hazardous alcohol use by the 10-items Alcohol Use Disorders Identification Test (AUDIT-10).

\section{Instruments}

Questionnaires comprised of a socio-demographic questions incorporating area of specialty in which participants work. As part of the demographics, participants were asked whether they had history of long standing health challenges such as diabetes, cardiovascular disorders, osteoarthritis or other chronic ill-health conditions. They were also asked whether they were currently experiencing any stressor in any area of their life. And those that indicated yes were asked to indicate the aspect(s) of life where they were experiencing stress.

The AUDIT, a self-rated 10-item questionnaire, was used to assess harmful and hazardous alcohol use. In this study, the AUDIT at cut-off of 5 and above was used, as this could clearly identify subjects with alcohol-related problems in Nigerians ${ }^{8,20}$. Those who had not taken alcohol in the last 12 months were termed abstainers, those with AUDIT scores of 1-4 were moderate users, those who scored 5-14 were hazardous users, and those who scored 15 and above were harmful users (alcohol dependence). They were further grouped into non-hazardous users and hazardous users i.e. those who scored 0-4 and those who scored 5 and above respectively.

The scores for each question on AUDIT ranged from 0 to 4, with the first response for each question (e.g. never) scoring 0 , the second (e.g. less than monthly) scoring 1, the third (e.g. monthly) scoring 2, the fourth (e.g. weekly) scoring 3, and the last response (e.g. daily or almost daily) scoring 4 . For questions 9 and 10, which only had three responses, the scoring was 0,2 and 4 (from left to right).

The twelve items General Health Questionnaire (GHQ12) was used to assess their psychological well-being or distress within the past few weeks. The GHQ is used to detect psychological distress and vulnerability to psychiatric disorders in the general population or non-psychiatric clinical settings.

In GHQ-12, the respondent is asked to compare one's recent psychological state with his or her usual state ${ }^{21}$. The four subscales derived through factor analysis - somatic symptoms, anxiety and insomnia, social dysfunction, and severe depression - have a 4 point scoring system using GHQ scoring (0-0-1-1).

The total of all the subscale scores gives information about the present mental status and the mean GHQ score for the population of respondents was taken as a rough indicator for the best cut-off point as suggested by Goldberg et al and Zulkefly et $\mathrm{al}^{22,23}$. A cutoff of 2 was taken to identify at risk individuals experiencing psychological distress. The GHQ has been widely used in Nigeria, ${ }^{5,8}$. GHQ has a wellestablished reliability and validity and high sensitivity and specificity. It has been widely used for both case identification and as an indicator of psychological distress ${ }^{8,24}$.

\section{Ethical Approval}

Prior to data collection, permission was obtained from the Ethics Committee of the hospital. The instructions for completion of the questionnaires, a consent form, and a declaration on the anonymity and confidentiality of the respondents were attached to the questionnaire. Those respondents with AUDIT score indicating hazardous or harmful use were given simple advice, and brief counseling and opportunity for further assistant by clinical psychologists.

\section{Statistical Analysis}

A descriptive statistics was performed to determine the distribution of characteristics of all the variables studied, including the participants' alcohol use as assessed by AUDIT and level of psychological well-being as assessed by GHQ12.

The total, means and standard deviation for the GHQ and AUDIT scores were calculated. Chi square tests with Yates correction (used where the count in a cell of two by two table was less than 5) were used to describe relationships between respondent's characteristics and GHQ scores, and AUDIT as appropriate. The participants were dichotomized into surgical (those in $O \& G$, Surgery and accident/ emergency department) and non-surgical (including those in medicine, paediatrics, psychiatry department, pharmacists and laboratory technologists). The level of significance was set at $\mathrm{P}<0.05$.

\section{Results}

A total of 294 health workers were targeted during the course of the study. Of these, 256 were accessible and interviewed given $89 \%$ response rate (114 of 118 Doctors, 121 of 146 nurses and 21 of 25 others (Pharmacists and Laboratory Scientists). Table 1 presents the respondents' background information.

The descriptive analysis showed that the age of the participants spanned from 20 to 65 years with a mean of $34.71 \pm 12.72$ and mean GHQ score for the sample was $0.97 \pm 1.83$. Using the cut-off point of 2, $212(82.8 \%)$ of the respondents were psychologically healthy while the remaining $44(17.2 \%)$ were experiencing psychological distress.

A larger proportion of the participants were males (50.8\%), within the age group 30-39 (43.8\%), married (65.6\%), and had only practiced for less than ten year $(67.2 \%)$. Most $(66.4 \%)$ of them were practicing in non-surgical specialties. The pattern of alcohol consumption is shown in table 2 . The AUDIT scores ranges from 0 to 28 with a mean of $1.09 \pm 3.47$. Majority of the participants $192(75.0 \%)$ were abstainers, $49(19.1 \%)$ were moderate users while the rest $(5.9 \%)$ were either harmful or hazardous users.

Table 3 shows the relationship between subjects' characteristics and hazardous alcohol use. Only one woman $(0.8 \%)$ was found to be consuming alcohol hazardously against $10.8 \%$ of men. Significantly, men used alcohol hazardously more than women $(\mathrm{p}=0.003)$.

A greater proportion of health workers classified as others use alcohol hazardously, and the relationship between profession and hazardous alcohol use was also found to be significant $(p=0.001)$. However, there was no statistically significant relationship between marital status, age group and hazardous alcohol use. 
Table 1: Subject characteristics

\section{Variables}

Gender

Male

Female

$130(50.8)$

$126(49.2)$

Age groups

$<30$

30-39

40-49

50-59

60-69

$82(32.0)$

$112(43.7)$

$36(14.1)$

$23(9.0)$

3 (1.2)

Marital status

Single

86 (33.6)

Married

168 (65.6)

Widow/widower

Duration of practice

$<10$

10-19

$20>$

Specialty

Non-surgical

Surgical

Religion

Christianity

Islam

Professions

Doctors

$114(44.5)$

Nurses

Others

119 (46.5)

$23(9.0)$

Presence of Chronic illness

Non

Yes

113 (92.6)

$9(7.4)$

Stressor

Yes

76 (29.7)

$180(70.3)$

No

GHQ Scores

Normal

$212(82.8)$

Distress

As shown in table 4, similar proportion of men (18.5\%) and women $(15.5 \%)$ had a GHQ score indicating psychological distress and the association between gender and GHQ Scores was not statistically significant $(\mathrm{p}=0.583)$. All those who were

Table 2: Alcohol Consumption pattern of

\section{Participants}

$\begin{array}{lc}\text { Alcohol Use Pattern } & \text { Total n\% } \\ \text { Abstainers } & 192(75.0) \\ \text { Moderate Users } & 49(19.1) \\ \text { Hazardous Use } & 11(4.3) \\ \text { Harmful Use } & 4(1.6) \\ \text { Mean AUDIT Score } & 1.09( \pm 3.470)\end{array}$

Tables 3: Respondents' characteristics and Hazardous Alcohol Use

$\begin{array}{lccc}\begin{array}{l}\text { Subjects } \\ \text { characteristics }\end{array} & \begin{array}{c}\text { Non-hazardous Use } \\ \mathbf{n}(\%)\end{array} & \begin{array}{c}\text { Hazardous Use } \\ \mathbf{n}(\%)\end{array} & \text { Statistics } \\ \text { Professions } & 108(94.7) & 6(5.3) & \chi^{2}=11.934, \mathrm{p}=0.003 \\ \text { Doctors } & 115(96.6) & 4(3.4) & \\ \text { Nurses } & 18(78.3) & 5(21.7) & \\ \text { Others } & & & \\ \text { Gender } & 116(89.2) & 14(10.8) & \chi^{2}=2.504, \quad \mathrm{p}=0.001 \\ \text { Male } & 125(99.2) & 1(0.8) & \\ \text { Female } & & \end{array}$

Age groups

\begin{tabular}{|c|c|c|c|}
\hline$<40$ & $186(94.9)$ & $10(5.1)$ & $\chi^{2}=5.881, p=0.351$ \\
\hline$\geq 40$ & $55(91.7)$ & $5(8.3)$ & \\
\hline
\end{tabular}

Marital Status

Single $79(91.9) \quad 7(8.1) \quad \chi^{2}=1.302, \mathrm{p}=0.522$

Married $\quad 160(95.2) \quad 8(4.8)$

Widow/widower $\quad 2(100.0) \quad 0(0)$

Presence of Chronic illness

\begin{tabular}{|c|c|c|}
\hline Yes & $11(78.6)$ & $3(21.4)$ \\
\hline No & $230(95.0)$ & $12(5.0)$ \\
\hline
\end{tabular}

widows or widowers were experiencing psychological distress and the association between marital status and GHQ scores was significant. Similarly, there was statistically significant relationship between years of practice, specialty of practice, the presence of chronic illness or current stressor and high GHQ score $(\mathrm{p}<0.05)$.

The relationship between level of alcohol use and GHQ is as shown in table 5. Majority of those who were using alcohol either hazardously $(88.9 \%)$ or harmfully $(75.0 \%)$ were GHQ positive. The relationship between levels of alcohol use and GHQ score was found to be statistically significant $(\mathrm{p}=0.000)$. 
Table 4: Subjects characteristics in relationship to

\section{Psychological distress}

\begin{tabular}{|c|c|c|c|}
\hline $\begin{array}{l}\text { Subjects } \\
\text { characteristics }\end{array}$ & $\begin{array}{r}\text { GHQ score } \\
\text { (normal) }\end{array}$ & $\begin{array}{l}\text { GHQ Score } \\
\text { (indicating distress) }\end{array}$ & Statistics \\
\hline \multicolumn{4}{|l|}{ Gender } \\
\hline Male & $106(81.5)$ & $24(18.5)$ & $\chi^{2}=0.301, \quad p=0.583$ \\
\hline Female & $106(84.1)$ & $20(15.5)$ & \\
\hline \multicolumn{4}{|l|}{ Marital Status } \\
\hline Singles & $67(77.9)$ & $19(21.1)$ & $\chi^{2}=12.534, p=0.002$ \\
\hline Married & $145(86.3)$ & $23(13.9)$ & \\
\hline Widows/Widowers & $0(0)$ & $2(100)$ & \\
\hline \multicolumn{4}{|l|}{ Age groups } \\
\hline$<40$ & $46(76.7)$ & $14(23.3)$ & $\chi^{2}=2.080, p=0.149$ \\
\hline$\geq 40$ & $166(84.7)$ & $30(15.3)$ & \\
\hline
\end{tabular}

Years of practice

$\begin{array}{lrrr}<10 & 149(86.6) & 23(13.4) & \chi^{2}=6.867, \mathrm{p}=0.032 \\ 10-19 & 40(71.4) & 16(28.6) \\ >20 & 23(82.1) & 5(17.9)\end{array}$

Religion

Christianity

$202(83.5)$

$10(71.4)$

$40(16.5)$

Islam

$4(2.4)$

Profession

Doctors

$97(85.1)$

17 (14.9)

99 (83.2)

20 (16.8)

$16(69.6)$

7 (30.4)

Others

Specialty

Non-surgical

$135(79.4)$

35 (20.6)

Surgical

77 (89.5)

$9(10.5)$

Presence of Chronic illness
Yes

No

$$
8(57.1)
$$$$
204(84.3)
$$

$6(42.9)$

$38(15.7)$

Current Stressor

No

$$
166(92.2)
$$

46 (60.5) $\chi^{2}=3.263, \mathrm{p}=0.196$

$\chi^{2}=4.112, \mathrm{p}=0.043$

$\chi^{2}=6.856, p=0.009$

$\chi^{2}=37.718, p=0.000$ $\chi^{2}=1.348, p=0.205$

\section{Discussion}

The findings from this study showed that majority of the health workers had not used alcohol in the past year and only about 6 percent were either hazardous or harmful drinkers. Also, nearly a fifth of the participants had significant score on GHQ 12 indicating psychological distress. When compared with the general population ${ }^{19}$, and other health workers elsewhere, ${ }^{14}$ healthcare professionals in this study appear to drink less. Our findings also suggest that those that constitute others (pharmacists and laboratory
Table 5: Level of alcohol use and psychological distress

\begin{tabular}{lcc}
$\begin{array}{l}\text { Level } \\
\text { of alcohol }\end{array}$ & $\begin{array}{c}\text { GHQ Scores } \\
\text { (normal) }\end{array}$ & \multicolumn{2}{c}{ GHQ Scores } \\
(indicting distress)
\end{tabular}

Statistics

$\chi^{2}=44.263, p=0.000$

technicians) use significantly more alcohol than other groups of healthcare professionals; however this observation may possibly have resulted from their small number, hence the validity of the association. The lower rate of alcohol use reported among health workers may have resulted from their knowledge of negative consequences of alcohol, hence caution in the use of alcohol. The proportion of doctors reported to be drinking harmfully in this study is similar to what was reported by Issa et al among doctors at the teaching hospital at Ilorin, Nigeria ${ }^{8}$ A higher rate of hazardous alcohol use among doctors compared to nurses was also observed; however this may have been influenced by the female dominance of the nursing profession. Generally, females drink less than men. Asides profession of the participants and gender, having an ongoing chronic illness like diabetes, hypertension, arthritis or history of current stressor predict hazardous or harmful alcohol use. Studies have reported association between gender, chronic illness like hypertension and harmful alcohol use ${ }^{14,} 26,27,28$. However, it might be difficult to categorically ascertain this, as chronic illness was based only on information given by the participants rather than objective assessment.

In this study, almost a fifth of health workers had GHQ scores indicating psychological distress. This finding showed that the proportion of the health workers who were psychologically healthy was about three times higher than those who were vulnerable to develop and experience psychological problems. This seems to suggest that a substantial proportion of health workers have the potential to develop and experience psychological problems. Compared with earlier report by Araujo et al, our finding showed relatively lower proportion of health workers were experiencing psychological distress ${ }^{29}$. The difference in socio-economic state and the environment in which the participants practice may account for this.

Several factors were found to predict psychological distress as indicated by a positive GHQ score. One of these is the subject's marital status. All those who were either a widow or widower were experiencing psychological distress. This association can be explained in term of additional burden of caring for family alone by those who were either widow or widowers and other emotional response from loss of one's spouse. Besides marital status, significant proportion of those who have practiced for between 10 and 20 years were also more likely to experience psychological distress. People at this period of practice are likely to be at the mid of their career, also coping with stress of career actualization and child rearing. They are more likely to have children or adolescents, and the need to meet greater financial obligations. In essence, they are in a period of life where 
everything is under construction. This mobilization of resources, which is added to the tensions emerging from this phase of their career, may explain why the tension generated by certain working conditions can be more pronounced for workers at this stage $\mathrm{e}^{30,31}$.

Being a doctor, nurse or other health worker did not predict psychological distress, however, the specialty in which one practices may be relevant. A greater proportion of those who work in the non-surgical specialty do experience psychological distress. This may be due to the burden of work-load from caring for those with both infectious and non-communicable diseases and the poor health workers patients' ratio in the developing countries ${ }^{32,33}$. Our study also found significant association between the presence of chronic illness (such as ongoing diabetes, hypertension or arthritis) and experiencing psychological distress. This, however, was not too surprising as these illnesses themselves may predispose to psychological distress $\mathrm{s}^{34,35,36}$ asides the challenges of caring for the sick in this part of the world.

Most of the health-workers who were either using alcohol hazardously or harmfully were experiencing psychological distress. Studies have shown that people with alcohol use disorders are more likely to experience psychological distress than those without $\operatorname{such}^{10,11,37,38}$. Alcohol use can occur alongside with general psychological distress and specific psychiatric disorders with increased risks for morbidity and mortality, as well as significant socio-economic costs. ${ }^{8,38,39}$ Studies have shown association between psychological or emotional distress and alcohol use , $^{8,10,38}$. Nevertheless, establishing a definite causal relationship is complex. Regardless of the relationship, people who abuse alcohol are prone to occupational and other health problems that make them vulnerable to developing psychological distress ${ }^{19,40}$. On the other hand, some people with certain psychological distress may engage in alcohol as means of coping ${ }^{40}$. The association between psychological distress and negative drinking consequences has been reported to be stronger among men than women ${ }^{41}$. Emotional distress and alcohol misuse however, may be functionally equivalent responses to stress by both genders ${ }^{42}$. On the other hand, this may represent differences in gender socialization where women tend to exhibit more internalizing problems; holding in negative emotions and turning them against themselves and men, as well exhibiting more externalizing problems such as alcohol mis-use ${ }^{43,44}$. However, some other studies have shown that abstainers have poorer mental health compared with moderate drinkers ${ }^{40,45,46}$.

\section{Limitations of the study}

The study is limited in that this is a cross sectional study and therefore causality cannot be ascertained. Besides, the study was conducted in just one hospital in the country with limited participants; this makes it difficult to generalize the findings. However, the study is one of the few studies looking at pattern of alcohol use, psychological distress and the relationship between alcohol use and psychological distress among health workers in a setting like ours; where there is inadequate health worker. It provides basic information on alcohol use, psychological health of health workers and relationship between the two.

\section{Conclusion}

Most of the participants in this study were abstainers, and a significant number of health workers were experiencing psychological distress. Psychological distress, however, was only accounted by harmful alcohol use, some sociodemographics and work related factors. Efforts should be geared towards identifying these factors to ensure effectiveness and efficiency of health workers on their job.

\section{Acknowledgement}

We acknowledge all the residents who assisted in data collection.

\section{Source of funding}

None

\section{Conflict of Interest}

None declared

\section{References}

1. Room R, Babor T, Rehm J. Alcohol and public health. Lancet 2005; 365 (9458): 519-530.

2. Lasebikan VO \& Ola BA. Prevalence and Correlates of Alcohol Use among a Sample of Nigerian Semirural Community Dwellers in Nigeria. Journal of Addiction.2016; Article ID 2831594, 6 pages http:// dx.doi.org/10.1155/2016/2831594.

3. Chukwuonye II, Chuku A, Onyeonoro UU Madukwe OO, Oviasu E , Ogah OS. A rural and urban cross-sectional study on alcohol consumption among adult Nigerians in Abia state. Int $\mathrm{J}$ Med Biomed Res 2013; 2(3):179-185.

4. Adewuya AO, Ola BA, Aloba OO, Mapayi MB, O I Ibigbami, Adewumi TA. Alcohol use disorders among Nigerian University students: Prevalence and Sociodemographic correlates. Niger J Psychiatry 2007; 5(1): 5-9.

5. Abayomi O, Onifade PO, Adelufosi AO, Akinhanmi AO. Psychosocial correlates of hazardous alcohol use among undergraduates in southwestern Nigeria. Gen Hosp Psychiatry. 2013; 35(3): 320-4.

6. Babalola EO, Akinhanmi A, Ogunwale A. Who guards the guards: Drug use pattern among medical students in a Nigerian University, Ann Med Health Sci Res. 2014; 4: 397-403.

7. Bello S, Fatiregun A, Ndifon WO, Oyo-Ita A, Ikpeme B. Social determinants of Alcohol use among drivers in Calabar. Niger Med J. 2011; 52: 244-9.

8. Issa BA, Yussuf AD, Abiodun OA, Olanrewaju GT, Kuranga TO. Hazardous Alcohol Use among Doctors in a Nigerian Tertiary Hospital. West Afr J Med. 2012 Mar-Apr; 31(2): 97-101.

9. Aguocha GU, Onyeama GM, Bakare MO, Igwe MN. Alcohol use problems among Resident Doctors in a Nigerian Tertiary Hospital. J Pioneer Med Sci.2016; 5 (9): 2-13.

10. Foulds J, Wells JE, Lacey C, Adamson S, Sellman JD, Mulder R. A comparison of alcohol measures as predictors of psychological distress in the New Zealand population. ijadr.2013; 2(1): 59-67.

11. Balogun O, Koyanagi A, Stickley A, Gilmour S, Shibuya K. Alcohol Consumption and Psychological Distress in Adolescents: A Multi-Country Study. J Adolesc Health 2014; 54(2): 228-234.

12. Gossop M, Stephens S, Stewart D, Marshall J, Bearn J and Strang J. Health care professionals referred for treatment of alcohol and drug problems. Alcohol. 2001; 36 (2): 160-164.

13. Bohigian GM, Groughan JL, Sanders K. Substance abuse and dependence in physicians: an overview of the effect of alcohol and drug abuse. Mo Med. 1994; 91: 233-9.

14. Kenna GA, Wood MD. Alcohol use by healthcare professionals. Drug Alcohol Depend. 2004; 75(1):107-16.

15. Nash LM, Daly MG, Kelly PJ, van Ekert EH, Walter G, Walton M,et al. Factors associated with psychiatric morbidity and hazardous alcohol use in Australian doctors. Med J Aust. 2010; 193(3):161-6. 
16. Judith Rosta Prevalence of problem-related drinking among doctors: a review on representative samples. German Medical Science. 2005; Vol. 3, ISSN 1612-3174.

17. Roster J. Hazardous alcohol use among hospital Doctors in Germany. Alcohol Alcohol. 2008; 43(2):198-203.

18. Romelsjö A, Hasin D, Hilton M, Boström G, Diderichsen F, Haglund $\mathrm{B}$ et al. The relationship between stressful working conditions and high alcohol consumption and severe alcohol problems in an urban general population. Br J Addict. 1992; 87(8):1173-1183.

19. Rosta J, Gerber A. Excessive working hours and health complaints among hospital physicians: a study based on a national sample of hospital physicians in Germany. Ger Med Sci. 2007 Nov 29; 5: Doc09.

20. Adewuya AO. Validation of the alcohol use disorders identification test (AUDIT) as a screening tool for alcohol-related problems among Nigerian university students. Alcohol Alcohol. 2005; 40: 575-77.

21. Goldberg DP, \& Williams P. A user's guide to the General Health Questionnaire. Windsor UK: NFER-Nelson; 1988.

22. Goldberg, D, Oldehinkel T, and Ormel J. Why GHQ threshold varies from one place to another. Psychol Med 1998; 28 (4): 915-21.

23. Zulkefly NS, Baharudin R. Using the 12-item General Health Questionnaire (GHQ-12) to Assess the Psychological Health of Malaysian College Students. Glob J Health Sci. 2010; 2(1): 73-80. http://dx.doi.org/10.5539/gjhs.v2n1p73

24. Goldberg DP, Hillier VF. A scaled version of the general health questionnaire. Psychol Med 1979; 9:139 45.

25. Gureje O, Degenhardt L, Olley B, Uwakwe R, Udofia O, Wakil A, et al. A descriptive epidemiology of substance use and substance use disorders in Nigeria during the early 21 st century. Drug Alcohol Depend. 2007; 91: 1-9.

26. Husain K, Ansari RA, Ferder L. Alcohol induced hypertention: Mechnism and prevention. World J Cardiol. 2014; 6 (5): 245-52.

27. Sesso HD, Cook NR, Buring JE, Manson JE, Gaziano JM. Alcohol consumption and the risk of hypertension in Women and Men. hyper. ahajournals. 2008; 51: 1080-1087.

28. Conigrave KM, Hu BF, Carmago CA, Stampfer MJ, Willett WC, Rimm EB. A prospective study of drinking patterns in relation to risk of type 2 diabetes among men. diabetes.diabetesjournals 2001; 50: 23902395.

29. Araújo TM, Aquino E; Menezes G; Santos O; Aguiar L. Work psychosocial aspects and psychological distress among nurses rev. Saúde pública vol.37 n.4 são paulo aug. 2003 http://dx.doi.org/10.1590/ s0034-89102003000400006.

30. Magnavita N, Fileni A, Magnavita G, Mammi F, Mirk P, Roccia K, Bergamaschi A: Work stress in radiologists. A pilot study. Radiol Med. 2008; 113(3):329-346.

31. Bartram DJ, Yadegarfar G, Baldwin DS: Psychosocial working conditions and work-related stressors among UK veterinary surgeons. Occup Med. 2009; 59(5):334-341.

32. The World Bank. Physicians (per 1,000 people) http:// data.worldbank.org/indicator/SH.MED.PHYS.ZS

33. Madhav GD. "Doctor population ratio for India - The reality". Indian J Med Res. Apr 2013; 137(4): 632-635.
34. Hamer M, Batty GD, Stamatakis E, Kivimaki M. Hypertension Awareness and Psychological Distress. hyper.ahajournals.2010; $56: 547-550$.

35. Virtanen M, Ferrie JE, Tabak AG, Akbaraly TN, Vahtera J, SinghManoux A, et al Psychological distress and incidence of type 2 diabetes in high-risk and low-risk populations: the Whitehall II Cohort Study. care.diabetesjournals. 2014; 37(8): 2091-7.

36. Egede LE \& Dismuke CE. Serious psychological distress and diabetes: a review of the literature. Curr Psychiatry Rep. 2012; 14(1):15-22.

37. Kessler, R. C., Crum, R. M., Warner, L. A., Nelson, C. B., Schulenberg, J., Anthony, J. C. Lifetime co- occurrence of DSM-III-R alcohol abuse and dependence with other psychiatric disorders in the National Comorbidity Survey. Archives of General Psychiatry 1997; 54: $313-321$

38. Li, T. K., Hewitt, B. G., \& Grant, B. F. Alcohol use disorders and mood disorders: A national institute on alcohol abuse and alcoholism perspective. biologicalpsychiatryjournal 2004; 56: 718-720.

39. Kessler RC, Chiu,WT, Demler, O, Merikangas, KR, \&WaltersEE. Prevalence, severity, and comorbidity of 12- month DSM-IV disorders in the National Comorbidity Survey Replication. Archives of General Psychiatry. 2005; 62: 617-627.

40. Lucas N, Windsor TD, Caldwell TM, Rodgers B. Psychological distress in non-drinkers: Associations with previous heavy drinking and current social relationships. Alcohol Alcohol. 2010; 45: 95-102.

41. Markman GI, Larimer ME, Neighbors C: The relationship among alcohol use, related problems, and symptoms of psychological distress: gender as a moderator in a college sample. Addict Behav 2004; 29(5):843-8.

42. Simon, Robin W. "Assessing Sex Differences in Vulnerability among Employed Parents: The Importance of Marital Status." JJ. Health Soc. Behav. 1998; 39:38-54.

43. Rosenfield S, Vertefuille J and McAlpine DD. “Gender Stratification and Mental Health: An Exploration of Dimensions of the Self." J. Soc. Psychol . 2000; 63:208-23.

44. Marta Elliott. Gender Differences in the Determinants of Distress, Alcohol Misuse, and Related Psychiatric Disorders. Soc. Ment. Health. 2013; 3(2): 96-113.

45. Rodgers B, Korten AE, Jorm AF. Christensen H, Henderson S, Jacob PA. Risk factors for depression and anxiety in abstainers, moderate drinkers and heavy drinkers. Addiction. 2000; 95: 1833-1845.

46. Alati R, Lawlor DA, Najman, JM, Williams GM, Bor W, O'Callaghan M. Is there really a 'J-shaped' curve in the association between alcohol consumption and symptoms of depression and anxiety? Findings from the Mater-University Study of Pregnancy and its outcomes. Addiction. 2005; 100: 643-651. 